\title{
Pre-perimetric glaucoma is not perimetry-free glaucoma
}

Abbreviations: PPG, pre-perimetric glaucoma; GON, glaucomatous optic neuropathy; VF, visual field; SAP, standard automated perimetry; RGC, retinal ganglion cell; $\mathrm{ONH}$, optic nerve head; RNFL, retinal nerve fibre Layer; OHT, ocular hypertension; OCT, optical coherence tomography

\section{Editorial}

Glaucoma is an irreversible, multifactorial, degenerative and progressive optic neuropathy characterized by the loss of retinal ganglion cells (RGCs) and their axons leading to thinning of the retinal nerve fiber layer (RNFL) and the loss of visual field (VF). Glaucoma is the second leading cause of preventable blindness over the world. Glaucomatous optic neuropathy (GON) usually firstly occurs in optic nerve head $(\mathrm{ONH})$ before detectable VF defects. It has been wellknown that glaucomatous VF defects might be detected in perimetry when $30-50 \%$ of RGCs was lost. ${ }^{1-6}$ The structural damages of the RNFL and optic disc precede VF loss detected by standard automated perimetry (SAP) in many eyes with early GON.A reduction in the thickness of the RNFL is an early sign of pre-perimetric glaucoma (PPG). ${ }^{1-6}$ Pre-perimetric glaucoma is defined as the presence of the signs of characteristic GON and the damage of RNFL before the development of VF defects. Hence, the conventional achromatic SAP can not reveal any VF defect in the cases with PPG. ${ }^{3-7}$

It has been demonstrated that $55 \%$ of patients of ocular hypertension (OHT) converted to those of treatment group based on optic disc changes without field changes. This means that almost a half of OHT cases will convert to PPG. Additionally, it has been also showed that, in almost $60 \%$ of OHT, RNFL defects were observed in approximately 6 years before VF loss in SAP was developed. ${ }^{6,7}$ It is also known that PPG is an early stage of primary open-angle glaucoma or early stage glaucoma. In numerous studies, it has been demonstrated that in the quantitative and objective evaluation of the GON and the assessment RNFL loss for the early detection of patients with PPG, scanning laser polarimetry (GDx-VCC) and optical coherence tomography (OCT) provided accurate and reproducible data. ${ }^{8-14}$ In last years, it has been reported that OCT-angiography is a reliable, easy-to-perform method for the diagnosis of PPG. ${ }^{15,16}$ The correct evaluation of ONH and peripapillary and macular RNFL using ophthalmoscopy and OCT is still essential for PPG diagnosis. However, to diagnose PPG, perimetry is also essential. PPG is the glaucoma with normal perimetry or normal-perimetric glaucoma. In the other words, PPG is not perimetry-free glaucoma.

\section{Acknowledgments}

None.

\section{Conflicts of interest}

There are no conflicts of interest.

\section{Funding}

None.
Volume 7 Issue 4 - 2017

\author{
Burak Turgut, Feyza Çaliș Karanfil \\ Department of Ophthalmology, Yuksek Ihtisas University, Turkey
}

Correspondence: Burak Turgut, Professor of Ophthalmology, Yuksek Ihtisas University, Faculty of Medicine, Department of Ophthalmology, 06520, Ankara, Turkey, Tel +90 312280360 I, Fax +90 3122803605, Email burakturgut@yiu.edu.tr

Received:September 18, 2017 | Published: September 18, 2017

\section{References}

1. Jonas JB, Budde WM. Diagnosis and Pathogenesis of Glaucomatous Optic Neuropathy: Morphological Aspects. Prog Retin Eye Res. 2000;19(1):140 .

2. Mikelberg FS, Yidegiligne HM, Schulzer M. Optic nerve axon count and axon diameter in patients with ocular hypertension andnormal visual fields. Ophthalmology. 1995;102(2):342-348.

3. Ajtony C, Balla Z, Somoskeoy S, et al. Relationship between visual field sensitivity and retinal nerve fiber layer thickness as measured by optical coherence tomography. Invest Ophthalmol Vis Sci. 2007;48(1):258-263.

4. Kim HG, Heo H, Park SW. Comparison of scanning laser polarimetry and optical coherence tomography in preperimetric glaucoma. Optom Vis Sci. 2011;88(1):124-129.

5. Mardin C, Horn F, Jonas J, et al. Preperimetric glaucoma diagnosis by confocal scanning laser tomography of the optic disc. Br J Ophthalmol. 1999;83(3):299-304.

6. Ophir A. First-visit diagnosis of preperimetric glaucoma. Open Ophthalmol J. 2010;4:22-27.

7. Sommer A, Katz J, Quigley HA, et al. Clinically detectable nerve fiber atrophy precedes the onset of glaucomatous field loss. Arch Ophthalmol. 1991;109(1):77-83.

8. Sriram P, Klistorner A, Graham S, et al. Optimizing the Detection of Preperimetric Glaucoma by Combining Structural and Functional Tests. Invest Ophthalmol Vis Sci. 2015;56(13):7794-7800.

9. Kim YJ, Kang MH, Cho HY, et al. Comparative study of macular ganglion cell complex thickness measured by spectral-domain optical coherence tomography in healthy eyes, eyes with preperimetric glaucoma, and eyes with early glaucoma. Jpn J Ophthalmol. 2014;58(3):244-251.

10. Begum VU, Addepalli UK, Yadav RK, et al. Ganglion cell-inner plexiform layer thickness of high definition optical coherence tomography in perimetric and preperimetric glaucoma. Invest Ophthalmol Vis Sci. 2014;55(8):4768-4775.

11. Kim KE, Jeoung JW, Kim DM, et al. Long-term follow-up in preperimetric open-angle glaucoma: progression rates and associated factors. Am J Ophthalmol. 2015;159(1):160-168.e1-2. 
12. Lu AT, Wang M, Varma R, et al. Combining nerve fiber layer parameters to optimize glaucoma diagnosis with optical coherence tomography. Ophthalmology. 2008;115(8):1352-1357.

13. Kim TW, Park UC, Park KH, et al. Ability of Stratus OCT to identify localized retinal nerve fiber layer defects in patients with normal standard automated perimetry results. Invest Ophthalmol Vis Sci. 2007;48(4):16351641.

14. Bourne RR, Medeiros FA, Bowd C, et al. Comparability of retinal nerve fiber layer thickness measurements of optical coherence tomography instruments. Invest Ophthalmol Vis Sci. 2005;46(4):1280-1285.
15. Cennamo G, Montorio D, Velotti N, et al. Optical coherence tomography angiography in pre-perimetric open-angle glaucoma. Graefes Arch Clin Exp Ophthalmol. 2017.

16. Kim SB, Lee EJ, Han JC, et al. Comparison of peripapillary vessel density between preperimetric and perimetric glaucoma evaluated by OCTangiography. PLoS One. 2017;12(8):e0184297. 